\title{
Stenting and Angioplasty of Small Cerebral Arteries in Symptomatic Intracranial Atherosclerotic Disease
}

\author{
Osama O. Zaidat ${ }^{a-c}$ Junaid Kalia ${ }^{a}$ Emad Nourollah-Zadeh ${ }^{a}$ \\ Alicia C. Castonguay ${ }^{a}$ Marc Lazzaro $^{a, b}$ John Lynch $^{a-c}$ \\ Brian-Fred Fitzsimmons ${ }^{a-c}$ \\ Departments of ${ }^{a}$ Neurology, ${ }^{b}$ Neurosurgery and ${ }^{c}$ Radiology, Medical College of Wisconsin \\ and Froedtert Hospital, Milwaukee, Wisc., USA
}

\section{Key Words}

Intracranial atherosclerotic disease · Small intracranial arteries · Angioplasty · Stenting ·

Wingspan

\begin{abstract}
Background: Intracranial atherosclerotic disease (ICAD) is a common cause of stroke with a poor natural history despite medical therapy. Few studies have investigated endovascular therapies for the treatment of symptomatic ICAD in distal intracranial arteries. Here, we present the feasibility and safety of balloon angioplasty with and without stenting in patients with medically refractory small-artery symptomatic ICAD. Methods: Personal logs were reviewed to identify patients who were treated for small-artery ICAD (stenosis $>50 \%$ ) using angioplasty and/or stenting. Small cerebral arteries were defined by a diameter of $\leq 2 \mathrm{~mm}$ or any branch distal to a large intracranial vessel (i.e. distal to the internal carotid artery, M1, A1, or vertebrobasilar trunk). Patient characteristics, clinical manifestations, treatment, hospital course, and follow-up data were collected and analyzed. Results: Ten patients (12 arteries) were treated with either primary balloon angioplasty (58.3\%) or angioplasty with stenting (41.6\%) with a $100 \%$ technical success rate. Mean pretreatment stenosis was $79.9 \%$, while mean posttreatment stenosis was $19.0 \%$. There were no major periprocedural complications, including symptomatic intracranial hemorrhage or mortality; 3 cases were complicated by groin hematoma. Patients were followed for a mean total of 18.6 months with only 1 symptomatic restenosis which was retreated successfully. All patients had good functional outcome with a modified Rankin Scale of either 0 (80\%) or 1 (20\%) on follow-up. Conclusion: In our case series, treatment of symptomatic small-artery ICAD with angioplasty and/or stenting was safe and effective. These interventions should be considered as an alternative treatment for ICAD patients refractory to medical therapy.




\section{Introduction}

Intracranial atherosclerotic disease (ICAD), a common cause of acute ischemic stroke, accounts for $8-10 \%$ of cases in the United States and for as many as 33\% of cases in the Asian population [1, 2]. Unfortunately, ICAD has a high stroke recurrence rate that correlates with the severity of stenosis and, during the first year, can be as high as $18 \%$ for patients with $\geq 70 \%$ stenosis $[3,4]$. The natural history of ICAD is not well understood; however, it has been associated with age, hypertension, and diabetes mellitus [5]. Primary treatment of ICAD involves antiplatelet therapy, statins, and modification of cardiovascular risk factors such as hypertension, diabetes, and smoking. Unfortunately, despite medical treatment, many patients remain symptomatic. In the past, surgical approaches such as extracranial-intracranial arterial bypass have failed to show improved efficacy over medical treatment [6]; however, during the past decade, percutaneous transluminal angioplasty with stenting (PTAS) has become a prevalent rescue therapy in these patients. Currently, the Wingspan Stent System with Gateway ${ }^{\mathrm{TM}}$ balloon is the only Food and Drug Administration-approved PTAS device for ICAD patients refractory to medical therapy and stenosis of $\geq 50 \%$, and various studies have investigated its efficacy and safety since its introduction in 2005 [7-11]. The SAMMPRIS trial (Stenting vs. Aggressive Medical Therapy for Intracranial Arterial Stenosis) remains to be the only randomized controlled trial, reporting that aggressive medical management is superior to PTAS in large-artery ICAD treatment (artery diameter of 2-4.5 mm) [12].

Interestingly, there are very few studies looking at the feasibility of primary angioplasty or PTAS in small intracranial artery atherosclerosis. In this study, we will present our experience with primary angioplasty or PTAS of small-artery ICAD.

\section{Methods}

Following institutional review board approval, we retrospectively reviewed all angioplasty and PTAS cases performed by our group at the Medical College of Wisconsin from January 2005 through July 2009. Inclusion criteria included: (1) medically refractory and symptomatic ICAD patients with $\geq 50 \%$ stenosis in the same vascular territory using computed tomography angiography (CTA) or digital subtraction angiography (DSA) and (2) presence of small intracranial artery involvement (defined as arteries with a diameter of $\leq 2 \mathrm{~mm}$ or any distal branch of large intracranial arteries, i.e. distal to the M1, A1, or vertebrobasilar trunk). Exclusion criteria included: (1) non-atherosclerotic stenosis, cardioembolic source, antiplatelet contraindication, poor functional baseline [modified Rankin Scale (mRS) $\geq 2$ ] and (2) concomitant disease with survival $<2$ years. Of the 169 intracranial angioplasty and stenting procedures identified, 10 eligible patients (12 interventions) were selected for which demographic, procedural, radiographic, and clinical follow-up data were collected for at least 2 months. Functional outcome was measured using the mRS from patients' last known clinic visit with good outcome defined as $\mathrm{mRS} \leq 2$, and intracranial stenosis was measured as previously described [13]. All procedures were performed under general anesthesia, and our protocol included preprocedural heparin (2,000-6,000 units) and dual antiplatelet therapy with clopidogrel (75 mg) and aspirin (325 $\mathrm{mg}$ ) at least 3 days before and 3 months after procedure, when possible. Angioplasty was done using the Gateway balloon in all cases except 2 (Maverick ${ }^{\mathrm{TM}}$ balloon), and PTAS was performed using the Wingspan Stent System. Following the procedure, patients were monitored for $24 \mathrm{~h}$ in the neurointensive care unit.

\section{Results}

\section{Patient Characteristics}

The study included 10 patients ( 3 men and 7 women) with symptomatic small-artery ICAD and a mean age of 66.6 years (range 38-85 years). The mean time from initial symptom to interventional procedure was 4.8 months (ranging from 3 days to 6 months). There were 
Zaidat et al.: Stenting and Angioplasty of Small Cerebral Arteries in Symptomatic

Intracranial Atherosclerotic Disease

Table 1. Summary of characteristics, stenosis, treatment, and follow-up in patients with small-artery ICAD

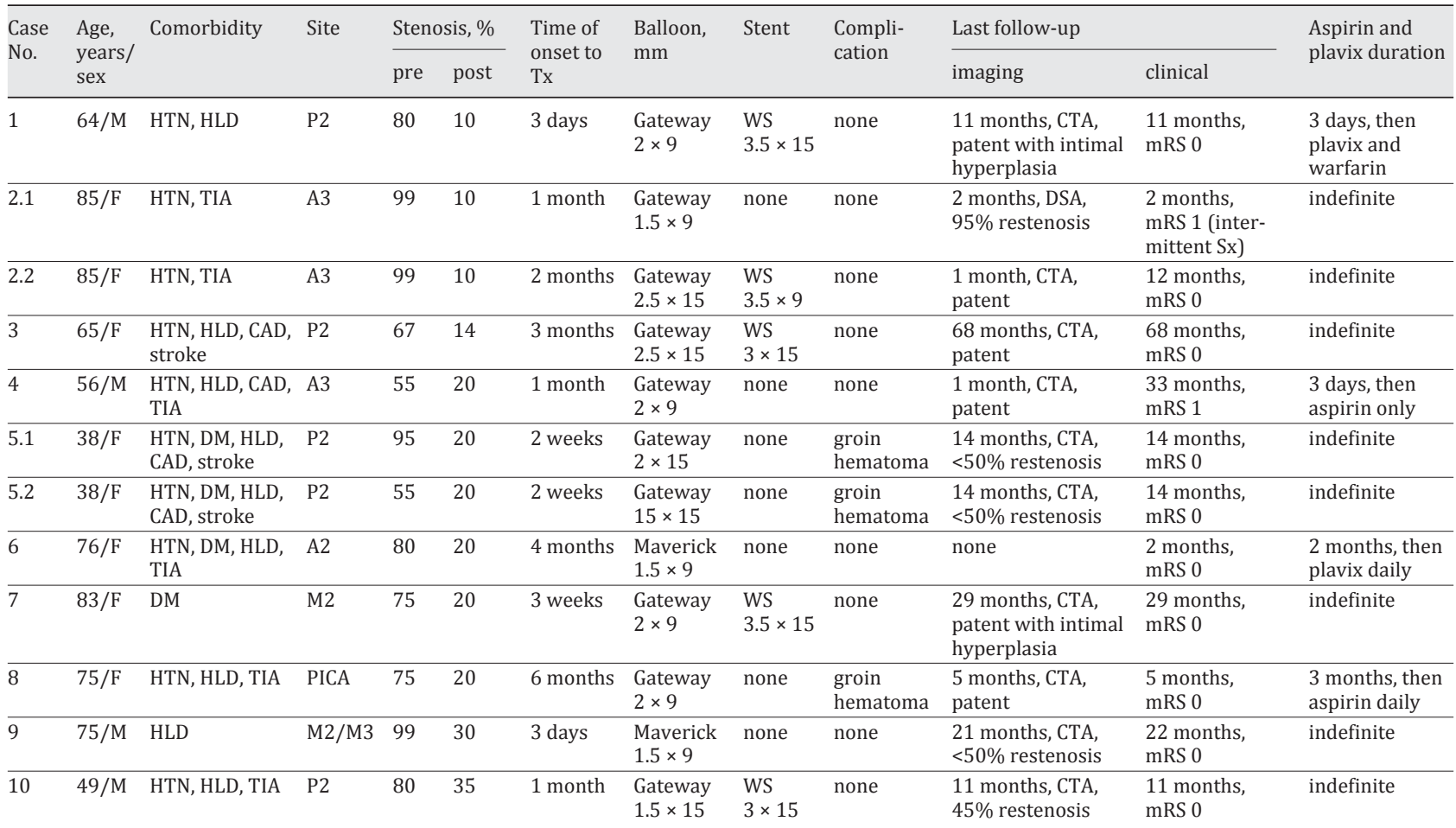

A = Anterior cerebral artery; $\mathrm{CAD}=$ coronary artery disease; $\mathrm{DM}=$ diabetes mellitus; $\mathrm{HLD}=$ hyperlipidemia; $\mathrm{HTN}=$ hypertension; $\mathrm{M}=$ middle cerebral artery $\mathrm{P}=$ posterior cerebral artery; PICA = posterior inferior cerebellar artery; $\mathrm{Sx}=$ symptoms; TIA = transient ischemic attack; Tx = treatment; WS = Wingspan.

12 lesions in 10 patients that were equally distributed in both anterior and posterior circulations (table 1). Both primary balloon angioplasty and PTAS with Wingspan were technically successful in all patients. The mean preprocedure stenosis was 79.9\% (range 55-99\%) with a mean residual stenosis of $19.0 \%$ (range 10-35\%). Primary balloon angioplasty was performed using either Gateway (71.4\%, 5 of 7 patients) or Maverick balloon (28.6\%, 2 of 7 patients), while Wingspan was used in all stenting procedures.

\section{Hospital Course and Complications}

The mean hospital stay for all patients was 6.8 days. There were no significant periprocedural complications, such as symptomatic intracranial hemorrhage or mortality; however, 3 patients developed groin hematomas.

\section{Follow-Up}

The initial clinical follow-up was done after a mean of 50.4 days and continued for a mean total of 18.6 months. Only 1 patient (No. 2) who underwent primary angioplasty returned with symptomatic restenosis necessitating retreatment with PTAS. The duration of dual antiplatelet treatment was indefinite for 6 patients, 2-3 months for 2 patients, and indefinite monotherapy for the other 2 patients due to either allergy or intolerance. Good functional outcome $(\mathrm{mRS} \leq 2)$ was seen in all patients at the time of their last follow-up.

\section{Example Case 1}

A 64-year-old Caucasian male with a history of dyslipidemia, pulmonary embolism, and transient ischemic attack presented to the emergency department with acute visual distur- 


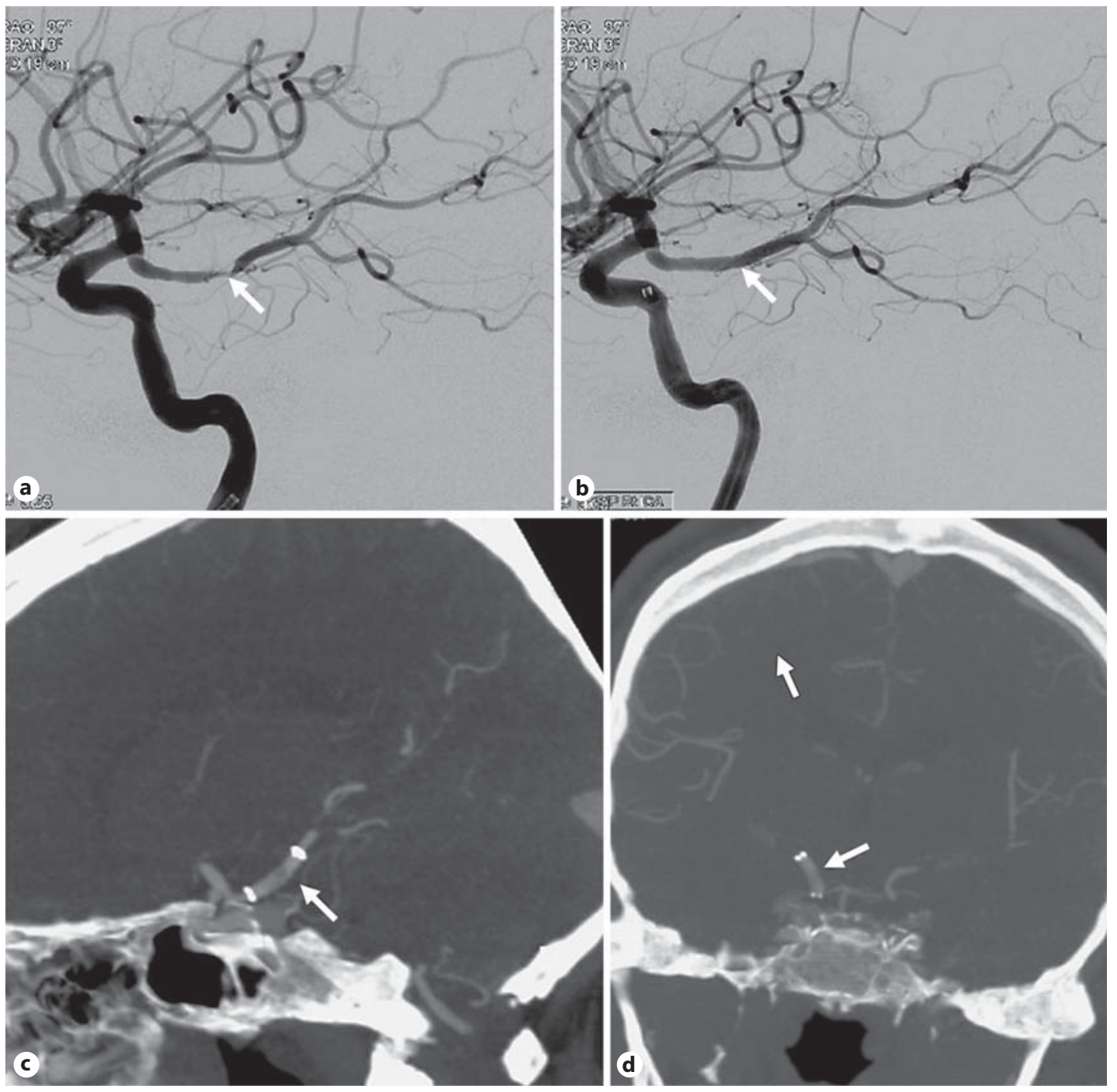

Fig. 1. A 64-year-old male presenting with visual disturbances and disequilibrium was found to have a $\geq 80 \%$ stenosis of the right P2 on DSA (a; arrow). The patient's symptoms resolved after PTAS with minimal $(\sim 10 \%)$ residual stenosis (b; arrow). After 11 months, follow-up CTA shows mild intimal hyperplasia on sagittal and coronal views (c and $\mathbf{d}$, respectively; arrows).

bance, headache, and disequilibrium. Initial CTA and subsequent DSA confirmed an 80\% stenosis within the right proximal P2 segment of the posterior cerebral artery (PCA) (fig. 1a). Since the patient was previously on maximal medical therapy, he successfully underwent angioplasty of the stenotic lesion via the right internal carotid posterior communicating arteries (Gateway balloon; $2 \times 9 \mathrm{~mm}$ ) with an inflation pressure reaching up to 10 atmospheres. The balloon was then exchanged for a Wingspan stent $(3.5 \times 15 \mathrm{~mm})$ with a residual stenosis of $10 \%$ (fig. 1b). The procedure was tolerated without any periprocedural complications and follow-up CTA of the head illustrated mild intimal hyperplasia after 11 months (fig. 1c, d). 

Intracranial Atherosclerotic Disease
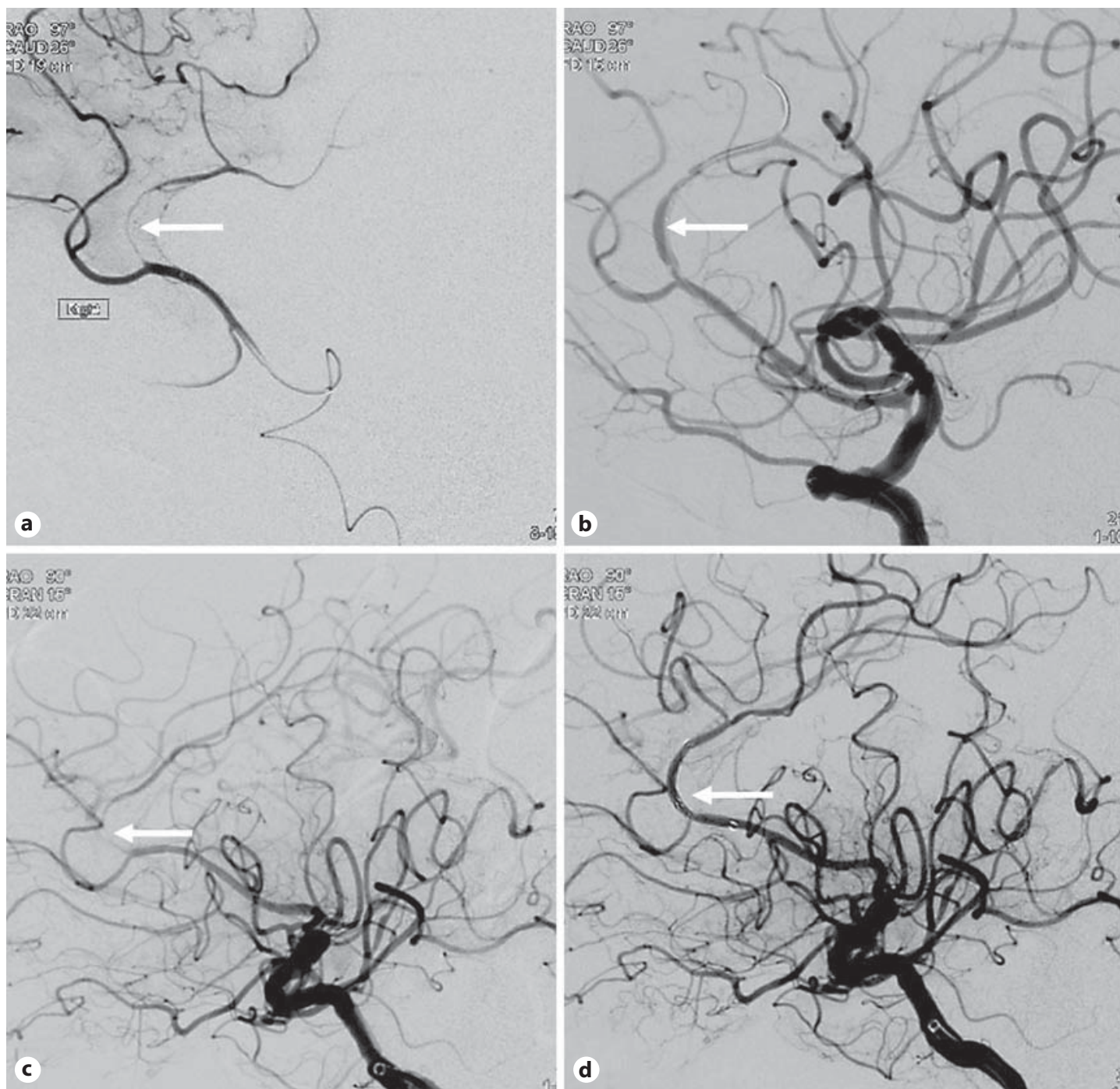

Fig. 2. An 85 -year-old female presenting with left lower extremity shaking was found to have $>95 \%$ stenosis of the right A3 portion of the anterior cerebral artery (a; arrow). Despite aggressive medical management, the patient continued to have recurrent symptoms and underwent successful primary balloon angioplasty (b; arrow). However, the patient returned with symptomatic restenosis (>95\%) after 1 month (c; arrow) and subsequently underwent PTAS through deployment of two Wingspan stents in a telescoping fashion into the right A3 lesion. Final angiography revealed minimal residual stenosis (d; arrow).

\section{Example Case 2}

An 85-year-old Caucasian female with a history of hypertension and transient ischemic attack presented with involuntary limb shaking and twitching of the left lower extremity. After excluding possible radiculopathy and seizure, magnetic resonance imaging (MRI) and MR angiography of the brain showed a right corpus callosum infarction and significant narrowing of the right anterior cerebral artery. The patient continued to have recurrent symptoms despite maximal medical therapy with repeat DSA after 6 months, showing right A3 stenosis (>95\%) $10 \mathrm{~mm}$ in length (fig. 2a). The patient was then treated with primary balloon angioplasty (Gateway balloon; $1.5 \times 15 \mathrm{~mm}$ ) as shown in figure $2 \mathrm{~b}$. However, after 1 month, the patient was readmitted for similar symptoms and was found to now have $>95 \%$ 

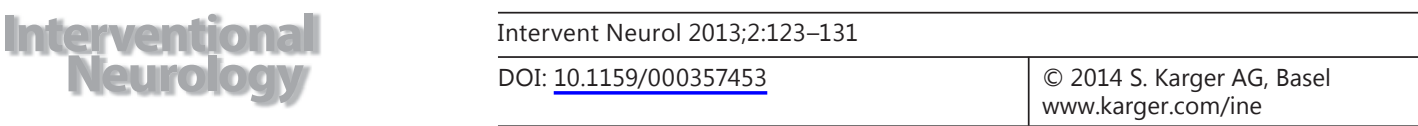

Zaidat et al.: Stenting and Angioplasty of Small Cerebral Arteries in Symptomatic Intracranial Atherosclerotic Disease
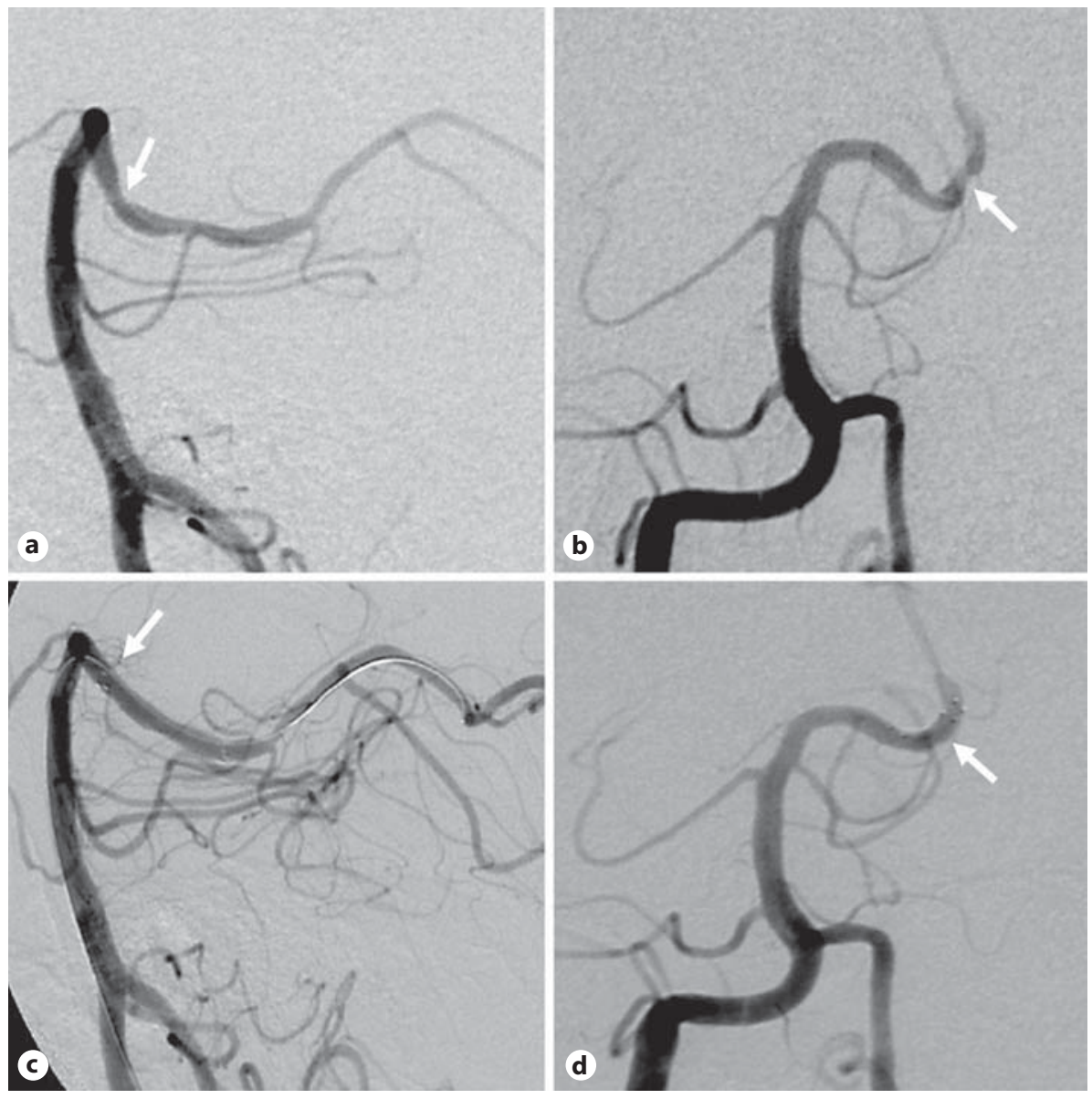

Fig. 3. A 65-year-old female with right lower extremity weakness was found to have small left thalamic and posterior internal capsule infarcts along with $67 \%$ stenosis in the left P2 segment of the PCA as shown in lateral and frontal views of selective left vertebral DSA ( $\mathbf{a}$ and $\mathbf{b}$, respectively; arrows). The patient underwent successful PTAS with the Wingspan Stent System with resultant 14\% residual stenosis as seen on frontal and lateral views (c and d, respectively; arrows).

restenosis (fig. 2c). She underwent PTAS of the right A3 vessel using the Wingspan Stent System with only a $10 \%$ residual stenosis as seen in figure $2 \mathrm{~d}$. No periprocedural complications occurred and the patient demonstrated a mRS of 0 at 12 months.

\section{Example Case 3}

A 65-year-old Caucasian female with a past medical history of hypertension, diabetes, and hyperlipidemia was admitted for right lower extremity weakness and was found to have left thalamic and posterior internal capsule strokes along with a high-grade stenosis of the left P2 segment (67\%, $11.6 \mathrm{~mm}$ in length) of the PCA (fig. 3a, b). Prior to the stroke, the patient was on maximal medical therapy (including dual antiplatelets). The patient underwent balloon angioplasty (Gateway balloon; $2.5 \times 15 \mathrm{~mm}$ ) with an inflation pressure up to 8 atmospheres, followed by successful deployment of Wingspan stent $(3 \times 15 \mathrm{~mm})$ across the lesion and minimal residual stenosis (fig. 3c, d). During her 5-year follow-up, she continued to have a widely patent stent on CTA and a good functional outcome $(\mathrm{mRS}=0)$. 
Zaidat et al.: Stenting and Angioplasty of Small Cerebral Arteries in Symptomatic Intracranial Atherosclerotic Disease

Table 2. Comparison of current data on endovascular treatment of small-artery ICAD [14-17]

\begin{tabular}{|c|c|c|c|c|c|c|c|c|c|c|}
\hline \multirow{2}{*}{$\begin{array}{l}\text { Study, } \\
\text { year }\end{array}$} & \multirow{2}{*}{$\begin{array}{l}\text { Site } \\
\text { (vessel cut off) }\end{array}$} & \multirow[t]{2}{*}{$\mathrm{n}$} & \multirow{2}{*}{$\begin{array}{l}\text { Stenosis } \\
\text { (mean), \% }\end{array}$} & \multirow{2}{*}{$\begin{array}{l}\text { Time of } \\
\text { onset to Tx }\end{array}$} & \multirow[t]{2}{*}{ Balloon } & \multirow[t]{2}{*}{ Stent } & \multirow{2}{*}{$\begin{array}{l}\text { Compli- } \\
\text { cation }\end{array}$} & \multirow[t]{2}{*}{ Restenosis } & \multicolumn{2}{|c|}{ Dual antiplatelet duration } \\
\hline & & & & & & & & & pre & post \\
\hline $\begin{array}{l}\text { Turk et al. [16], } \\
2007\end{array}$ & $\begin{array}{l}\text { A1, A2, M1, P1 } \\
(\leq 2 \mathrm{~mm})\end{array}$ & 4 & $>75$ & $>5$ days $(\mathrm{N} / \mathrm{A})$ & Maverick & $\begin{array}{l}\text { NF (3) or } \\
\text { WS (1) }\end{array}$ & none & $\begin{array}{l}1(25 \%) \\
(+S=0)\end{array}$ & 5 days & indefinite \\
\hline $\begin{array}{l}\text { Xu et al. [15], } \\
2009\end{array}$ & $\mathrm{P} 1(<2.5 \mathrm{~mm})$ & 1 & 85 & 2.5 months & Jostent & Jostent & none & 0 & 2 months & $\mathrm{N} / \mathrm{A}$ \\
\hline $\begin{array}{l}\text { Hussain et al. } \\
{[17], 2010}\end{array}$ & M2 $(\leq 2 \mathrm{~mm})$ & 5 & $85-95(90)$ & $>1$ day $(\mathrm{N} / \mathrm{A})$ & Gateway & none & none & $\begin{array}{l}2(40 \%) \\
(+S=2)\end{array}$ & $\geq 1$ day & 3 months \\
\hline $\begin{array}{l}\text { Zhang et al. [14], } \\
2012\end{array}$ & $\begin{array}{l}\text { ICA, M1/M2, PC } \\
(\leq 2.5 \mathrm{~mm})\end{array}$ & 39 & $50-90(73.9)$ & $1-45$ days $(23)$ & Gateway & WS & $1(\mathrm{sICH})$ & $\begin{array}{l}13(33.3 \%) \\
(+S=2)\end{array}$ & 3 days & 6 weeks \\
\hline Our study & $\begin{array}{l}\mathrm{A} 2, \mathrm{~A} 3, \mathrm{M} 2, \mathrm{M} 3, \mathrm{P} 2, \mathrm{PC} \\
(\leq 2 \mathrm{~mm})\end{array}$ & 10 & $55-95(79.9)$ & $\begin{array}{l}3 \text { days to } 6 \text { months } \\
\text { ( } 4.8 \text { months) }\end{array}$ & Gateway & WS & none & $\begin{array}{l}1(10 \%) \\
(+S=1)\end{array}$ & 3 days & $\begin{array}{l}\text { indefinite when } \\
\text { possible }(6 / 10)\end{array}$ \\
\hline
\end{tabular}

Jostent = Balloon-mounted bare metal stent (Abbot vascular, Germany); $\mathrm{n}=$ total number of patients; N/A = not available; NF = Neuroform stent (Boston scientific); $\mathrm{PC}=$ posterior circulation; $+\mathrm{S}=$ symptomatic in-stent restenosis; sICH = symptomatic intracranial hemorrhage; Tx = treatment; WS = Wingspan stent.

\section{Discussion}

It is estimated that up to $10 \%$ of all strokes in the US are due to ICAD [1]. Despite medical treatment, stroke recurrence can be as high as $18 \%$ within the first year for patients with severe stenosis $(\geq 70 \%$ ) [4]. Recently, SAMMPRIS, the only randomized controlled trial for endovascular treatment of ICAD, demonstrated the superiority of aggressive medical therapy over PTAS, as stroke recurrence occurred within the firstyear in 12.2 versus $20.9 \%$ of patients in the medical and PTAS arms, respectively. SAMMPRIS studied ICAD only in large intracranial arteries (2-4.5 mm); unfortunately, small-artery ICAD has not been studied extensively, and endovascular treatment may be a valuable alternative in medically refractory patients as large- and small-artery ICAD could possibly represent two distinct entities, with a different natural history and response to medical and interventional treatments (table 2) [14-17].

In our study, all 10 patients had symptomatic small-artery ICAD (mean stenosis of 79\%) refractory to medical therapy, and treatment with either primary balloon angioplasty or PTAS (Wingspan Stent System) yielded a 100\% technical success rate. This is comparable with other small-artery ICAD studies with reported success rates of 98.1-100\%, with the only technical difficulty due to failure of Wingspan stent deployment in a tortuous M2 lesion [1417]. Furthermore, there were no periprocedural complications in our patients, which is also similar to previously published case series (table 2). This could partially be explained by patient selection and operator experience with the Wingspan Stent System. In SAMMPRIS, about a third of periprocedural complications (symptomatic intracranial hemorrhage) were due to reperfusion injury or wire manipulation-related dissections which have been postulated to be related to operator inexperience with the Wingspan Stent System in some of the low-volume centers; it has also been previously shown that mastering the Wingspan Stent System has a significant learning curve [18].

Another important aspect is the post-intervention restenosis rate, which directly affects clinical outcome. The mechanism of restenosis after angioplasty or stenting is not well known. Factors like post-instrumentation, remodeling, vascular contraction, and/or inflammation are hypothesized $[19,20]$. Some of the risk factors for in-stent restenosis (ISR) include rapid balloon inflation, stent under-sizing, lesion length, diameter, and location (ISR occurs more frequently in the anterior circulation arteries) [21-24]. In this study, only 1 patient had restenosis (case 2.1; table 1), which occurred 1 month after primary angioplasty. The patient was retreated with PTAS with no further in-stent restenosis during follow-up. In other smallartery ICAD publications, the overall restenosis rate for primary angioplasty was $40.0 \%$ (all 
symptomatic) and $27.7 \%$ for PTAS (only $5.6 \%$ symptomatic) [14-17]. Studies examining large-artery ICAD have stated a variable in-stent restenosis rate for the Wingspan Stent System. The in-stent restenosis rate has been reported to be 7.5, 25 (3.8\% symptomatic), and $34.5 \%$ (9.5\% symptomatic) in the Humanitarian Device Exemption (HDE) study, NIH Multicenter Wingspan registry, and US Wingspan registry, respectively $[7,11,25,26]$. It is important to note that the majority of in-stent restenosis in patients treated for large-artery ICAD is asymptomatic. Additionally, in a meta-analysis of large-artery ICAD literature (1980-2008), a comparison of primary angioplasty versus PTAS treatment showed a trend for better outcome in patients treated with PTAS as both stroke incidence within the first year (19.7 vs. $14.2 \%, p=0.009$ ) and restenosis rate (14.2 vs. $11.1 \%, p=0.04$ ) were significantly lower in the PTAS group [27].

Lastly, in our study, all patients demonstrated good functional outcome on follow-up (mean of 18.6 months) with either a mRS of 0 or 1 . Unfortunately, functional outcome has not been consistently reported in other small-artery ICAD studies [14-17].

Limitations for this study include its retrospective data collection, selection bias, and small sample size.

\section{Conclusion}

Small-artery ICAD is an important cause of stroke and, given its poor natural history, there is an urgent need for alternative treatments for medically refractory patients. Endovascular treatment of small-artery ICAD is technically challenging given the small lumen size, tortuosity, and thin smooth muscle of small arteries; however, the advent of newer devices specific for distal cerebral arteries has made angioplasty and stenting possible. In this study, we showed that endovascular treatment of small-artery ICAD in a high-volume center could be both safe and effective in patients refractory to medical management. Although limited, current evidence demonstrates a trend for efficacy of endovascular treatment in small-artery ICAD, which may provide support for a randomized controlled trial.

\section{References}

1 Sacco RL, Kargman DE, Gu Q, Zamanillo MC: Race-ethnicity and determinants of intracranial atherosclerotic cerebral infarction. The northern Manhattan stroke study. Stroke 1995;26:14-20.

2 Wong LK: Global burden of intracranial atherosclerosis. Int J Stroke 2006;1:158-159.

- 3 Chimowitz MI, Lynn MJ, Howlett-Smith H, Stern BJ, Hertzberg VS, Frankel MR, et al: Comparison of warfarin and aspirin for symptomatic intracranial arterial stenosis. N Engl J Med 2005;352:1305-1316.

- 4 Kasner SE, Chimowitz MI, Lynn MJ, Howlett-Smith H, Stern BJ, Hertzberg VS, et al: Predictors of ischemic stroke in the territory of a symptomatic intracranial arterial stenosis. Circulation 2006;113:555-563.

5 Bae HJ, Lee J, Park JM, Kwon O, Koo JS, Kim BK, et al: Risk factors of intracranial cerebral atherosclerosis among asymptomatics. Cerebrovasc Dis 2007;24:355-360.

- 6 Failure of extracranial-intracranial arterial bypass to reduce the risk of ischemic stroke. Results of an international randomized trial. The EC/IC bypass study group. N Engl J Med 1985;313:1191-1200.

- 7 Fiorella D, Levy EI, Turk AS, Albuquerque FC, Niemann DB, Aagaard-Kienitz B, et al: US multicenter experience with the Wingspan stent system for the treatment of intracranial atheromatous disease: periprocedural results. Stroke 2007;38:881-887.

- 8 Fiorella DJ, Turk AS, Levy EI, Pride GL Jr, Woo HH, Albuquerque FC, et al: US Wingspan registry: 12-month follow-up results. Stroke 2011;42:1976-1981.

9 Jiang WJ, Cheng-Ching E, Abou-Chebl A, Zaidat 00, Jovin TG, Kalia J, et al: Multicenter analysis of stenting in symptomatic intracranial atherosclerosis. Neurosurgery 2012;70:25-30, discussion 31.

10 Jiang WJ, Yu W, Du B, Gao F, Cui LY: Outcome of patients with $\geq 70 \%$ symptomatic intracranial stenosis after Wingspan stenting. Stroke 2011;42:1971-1975.

11 Zaidat OO, Klucznik R, Alexander MJ, Chaloupka J, Lutsep H, Barnwell S, et al: The NIH registry on use of the Wingspan stent for symptomatic 70-99\% intracranial arterial stenosis. Neurology 2008;70:1518-1524. 
Zaidat et al.: Stenting and Angioplasty of Small Cerebral Arteries in Symptomatic Intracranial Atherosclerotic Disease

12 Chimowitz MI, Lynn MJ, Derdeyn CP, Turan TN, Fiorella D, Lane BF, et al: Stenting versus aggressive medical therapy for intracranial arterial stenosis. N Engl J Med 2011;365:993-1003.

13 Samuels OB, Joseph GJ, Lynn MJ, Smith HA, Chimowitz MI: A standardized method for measuring intracranial arterial stenosis. AJNR Am J Neuroradiol 2000;21:643-646.

14 Zhang L, Huang Q, Zhang Y, Liu J, Hong B, Xu Y, et al: Wingspan stents for the treatment of symptomatic atherosclerotic stenosis in small intracranial vessels: safety and efficacy evaluation. AJNR Am J Neuroradiol 2012; 33:343-347.

15 Xu G, Zheng L, Zhou Z, Liu X: Stenting for a symptomatic posterior cerebral artery stenosis. Catheter Cardiovasc Interv 2009;73:745-748.

16 Turk AS, Ahmed A, Niemann DB, Aagaard-Kienitz B, Brooks N, Levine RL: Utilization of self-expanding stents in the treatment of intracranial atherosclerotic disease in the distal small cerebral vessels. Neuroradiology 2007;49:659-663.

17 Hussain MS, Cheng-Ching E, Bain M, Spiotta AM, Sivapatham T, Hui F, et al: Initial experience with angioplasty of symptomatic M2 MCA atheromatous lesions. J Neurointerv Surg 2010;2:192-194.

18 Yu SC, Leung TW, Lee KT, Wong LK: Learning curve of Wingspan stenting for intracranial atherosclerosis: single-center experience of 95 consecutive patients. J Neurointerv Surg 2013, E-pub ahead of print.

19 Welt FG, Rogers C: Inflammation and restenosis in the stent era. Arterioscler Thromb Vasc Biol 2002;22 1769-1776.

20 Mintz GS, Popma JJ, Pichard AD, Kent KM, Satler LF, Wong C, et al: Arterial remodeling after coronary angioplasty: a serial intravascular ultrasound study. Circulation 1996;94:35-43.

21 Shin YS, Kim BM, Suh SH, Jeon P, Kim DJ, Kim DI, et al: Wingspan stenting for intracranial atherosclerotic stenosis: clinical outcomes and risk factors for in-stent restenosis. Neurosurgery 2013;72:596-604, discussion 604.

-22 Fiorella DJ, Levy EI, Turk AS, Albuquerque FC, Pride GL Jr, Woo HH, et al: Target lesion revascularization after Wingspan: assessment of safety and durability. Stroke 2009;40:106-110.

-23 Elezi S, Kastrati A, Neumann FJ, Hadamitzky M, Dirschinger J, Schomig A: Vessel size and long-term outcome after coronary stent placement. Circulation 1998;98:1875-1880.

24 Chen HY, Hermiller J, Sinha AK, Sturek M, Zhu L, Kassab GS: Effects of stent sizing on endothelial and vessel wall stress: potential mechanisms for in-stent restenosis. J Appl Physiol 2009;106:1686-1691.

25 Bose A, Hartmann M, Henkes H, Liu HM, Teng MM, Szikora I, et al: A novel, self-expanding, nitinol stent in medically refractory intracranial atherosclerotic stenoses: the Wingspan study. Stroke 2007;38:1531-1537.

-26 Levy EI, Turk AS, Albuquerque FC, Niemann DB, Aagaard-Kienitz B, Pride L, et al: Wingspan in-stent restenosis and thrombosis: incidence, clinical presentation, and management. Neurosurgery 2007;61:644-650, discussion 650-641.

27 Siddiq F, Memon MZ, Vazquez G, Safdar A, Qureshi AI: Comparison between primary angioplasty and stent placement for symptomatic intracranial atherosclerotic disease: meta-analysis of case series. Neurosurgery 2009;65:1024-1033, discussion 1033-1024. 